\title{
PENGARUH PENYULUHAN CARA MENYIKAT GIGI TERHADAP INDEKS PLAK GIGI PADA SISWA SD INPRES LAPANGAN
}

\author{
${ }^{1}$ Claudiette Brigita Pantow \\ ${ }^{2}$ Sarah M. Warouw \\ ${ }^{3}$ Paulina N. Gunawan
}

\author{
${ }^{1}$ Kandidat Skripsi Program Studi Pendidikan Dokter Gigi Fakultas Kedokteran \\ Universitas Sam Ratulangi Manado \\ ${ }^{2}$ Fakultas Kedokteran Universitas Sam Ratulangi Manado \\ ${ }^{3}$ Program Studi Pendidikan Dokter Gigi Fakultas Kedokteran Universitas Sam Ratulangi Manado \\ Email: pantowclaudiette@yahoo.com
}

\begin{abstract}
Dental health education conducted to the elementary school students is one of promotive effort to increase oral and dental health. The aim of this study was to know the influence of dental health education about tooth-brushing method toward dental plaque index in the elementary school students of Inpres Lapangan. Research was done in Inpres Lapangan elementary school using quasy experimental method. Samples were taken using total sampling method in a total of 50 respondents. This research used Wilcoxon statistical analysis test. The result showed that before dental health education conducted to the students dental plaque index was moderate category after dental health education conducted, dental plaque index increased to good category. Wilcoxon analysis test showed value of significance $p<0,001$. This statistical analysis concluded that there was influence of dental health education about tooth brushing method toward dental plaque index of the elementary students in Inpres Lapangan
\end{abstract}

Keywords: dental health education,tooth brushing method,plaque index

\begin{abstract}
Abstrak: Penyuluhan cara menyikat gigi pada siswa sekolah dasar merupakan salah satu upaya promotif dalam meningkatkan kesehatan gigi dan mulut anak. Tujuan penelitian ini ialah untuk mengetahui pengaruh penyuluhan cara menyikat gigi terhadap indeks plak gigi pada siswa SD Inpres Lapangan. Penelitian dilakukan di SD Inpres Lapangan, dengan menggunakan metode penelitian quasy eksperimental. Jumlah sampel yang diambil sebanyak 50 siswa dengan teknik pengambilan sampel yaitu total sampling. Penelitian ini menggunakan uji analisis statistik Wilcoxon. Hasil penelitian menunjukkan bahwa sebelum dilakukan penyuluhan cara menyikat gigi indeks plak awal ialah kategori sedang dan setelah dilakukan penyuluhan cara menyikat gigi indeks plak akhir ialah kategori baik. Hasil uji analisis statistik Wilcoxon ini menunjukkan $\mathrm{p}<0,001$. Hasil analisis ini menunjukan ada pengaruh yang bermakna dari penyuluhan cara menyikat gigi terhadap indeks plak gigi pada siswa SD Inpres Lapangan.
\end{abstract}

Kata kunci: penyuluhan kesehatan gigi, cara menyikat gigi, indeks plak 
Kesehatan gigi dan mulut di Indonesia masih perlu mendapat perhatian khusus dari tenaga kesehatan gigi dan mulut. Hal ini disebabkan karena sebagian besar masyarakat di Indonesia mengabaikan kesehatan gigi dan mulut mereka sendiri, termasuk anak usia sekolah dasar.

Kelompok anak usia sekolah dasar merupakan kelompok yang rentan terhadap penyakit gigi dan mulut sehingga perlu diperhatikan dan dicegah secara baik dan benar. Sebanyak 25,2\% anak berusia 10-14 tahun yang memiliki masalah gigi dan mulut di Indonesia. Kondisi ini dapat berpengaruh pada derajat kesehatan mereka dalam proses tumbuh kembang bahkan masa depan mereka. ${ }^{1,2,3}$

Selain peran orang tua dalam membimbing, memberikan pengertian dan mengingatkan anak untuk menjaga kesehatan gigi dan mulut, perlu dilakukan penyuluhan kesehatan gigi dan mulut oleh tenaga kesehatan. ${ }^{4,5}$ Penyuluhan kesehatan gigi dan mulut merupakan salah satu upaya untuk mencegah masalah kesehatan gigi dan mulut, dengan tercapainya tingkat kesehatan gigi yang lebih baik di masa mendatang. ${ }^{5}$

Usia anak sekolah dasar ialah saat yang tepat dimana seorang anak dilatih kemampuannya untuk menjaga dan memelihara kebersihan gigi dan mulut yaitu melalui cara menyikat gigi yang benar. Berdasarkan Riset Kesehatan Dasar (RISKESDAS) 2013 di Sulawesi Utara, persentase anak berusia usia 10-14 tahun yang menyikat gigi setiap hari ialah $95,7 \%$. Anak yang berusia diatas 10 tahun yang menyikat gigi setiap hari dan berperilaku menyikat gigi yang benar hanya sebesar 3,3\%. Anak yang menyikat gigi dengan benar hanya $1,7 \%$. $^{1}$

Pembersihan gigi yang kurang baik dapat menyebabkan terjadinya akumulasi plak. Salah satu cara menghilangkan plak yaitu dengan menyikat gigi. ${ }^{6}$ Plak adalah lapisan tipis, tidak berwarna, mengandung kumpulan bakteri, melekat pada permukaan gigi dan selalu terbentuk di dalam mulut dan bila bercampur dengan gula yang ada dalam makanan akan membentuk asam. ${ }^{6,7}$ Plak akan terlihat satu sampai dua hari apabila tidak ada langkah-langkah pembersihan mulut. ${ }^{8}$ Berdasarkan penelitian yang dilakukan Ilyas tentang efek penyuluhan metode demonstrasi menyikat gigi terhadap penurunan indeks plak gigi pada siswa sekolah dasar menyatakan bahwa terjadi penurunan nilai plak dari 3,5\% menjadi $1,2 \%{ }^{5}$

Berdasarkan latar belakang diatas, peneliti tertarik untuk melakukan penelitian sekaligus memberikan penyuluhan mengenai cara menyikat gigi pada siswa SD Inpres Lapangan. Penyuluhan tentang cara menyikat gigi belum pernah dilakukan di sekolah dasar ini, dan belum pernah ada tenaga kesehatan yang memberikan sosialisasi berupa penyuluhan cara menyikat gigi, sehingga penulis tertarik untuk melihat pengaruh penyuluhan tentang cara menyikat gigi terhadap indeks plak. Berdasarkan alasan-alasan tersebut, penulis mengangkat sebuah penelitian dengan judul "Pengaruh Penyuluhan Cara Menyikat Gigi Terhadap Indeks Plak Gigi Pada Siswa SD Inpres Lapangan".

\section{BAHAN DAN METODE}

Penelitian yang digunakan dalam penelitian ini yaitu desain penelitian quasy eksperimental dengan memeriksa indeks plak awal (pretest) dan sesudah dilakukan penyuluhan dengan memeriksa indeks plak akhir (posttest). Penelitian ini dilaksanakan di SD Inpres Lapangan pada bulan Maret-Juni 2014. Sampel yang digunakan ialah seluruh siswa kelas $\mathrm{V}$ dengan teknik pengambilan sampel yaitu total sampling yang memenuhi kriteria inklusi dan eksklusi berjumlah 50 siswa.

Penyuluhan cara menyikat gigi, yaitu penyuluhan yang diberikan kepada siswa dengan materi penyuluhan meliputi metode menyikat gigi dengan metode roll dan metode bass, pemilihan sikat gigi, frekuensi menyikat gigi. Setelah penyuluhan, peneliti memberikan pertanyaanpertanyaan berupa tes sederhana yang berisi tentang materi penyuluhan yang telah diberikan. Penyuluhan diberikan selama 15 menit.

Indeks plak gigi yaitu pengukuran indeks plak awal (pretest) dilakukan kepada siswa dengan menggunakan larutan disclosing solution". Sebelum diberikan penyuluhan dan pengukuran indeks plak akhir (posttest) ialah pengukuran indeks plak gigi dengan menggunakan larutan disclosing solution pada hari ketiga setelah diberikan penyuluhan cara menyikat gigi karena plak dapat terjadi pada satu sampai dua hari ketika tidak dilakukan pembersihan gigi dan mulut. 
Penilaian dan pemeriksaan dilakukan pada enam elemen gigi yang akan diperiksa, gigi $3,9,12,19,25$, dan 28 dengan penilaian setiap gigi pada bagian mesial, distal,bukal/labial,dan lingual/palatal. Akumulasi plak yang terlihat dicatat dan dihitung dengan menggunakan rumus indeks plak menurut Loe dan Sillnes, ${ }^{10}$ dan akan diberikan kategori yaitu sangat baik, baik, sedang, dan buruk.

IP/1 gigi= $\underline{\text { Jumlah empat permukaan gigi pada gigi }}$ 4

Indeks plak $=\Sigma$ Indeks plak gigi Jumlah gigi yang diperiksa

\section{HASIL PENELITIAN}

Tabel 1. Distribusi karakteristik responden berdasarkan jenis kelamin

\begin{tabular}{ccc}
\hline Jenis & $\mathrm{n}$ & $\%$ \\
Kelamin & & \\
\hline Laki-laki & 26 & 52 \\
Perempuan & 24 & 48 \\
\hline Total & 50 & 100 \\
\hline
\end{tabular}

Tabel 2. Distribusi karakteristik responden berdasarkan usia

\begin{tabular}{ccc}
\hline Usia & $\mathrm{n}$ & $\%$ \\
\hline 10 & 27 & 54 \\
11 & 23 & 46 \\
\hline Total & 50 & 100 \\
\hline
\end{tabular}

Tabel 3. Hasil pemeriksaan indeks plak gigi sebelum penyuluhan

\begin{tabular}{ccc}
\hline Kategori & $\mathrm{n}$ & $\%$ \\
\hline Sangat Baik & 0 & 0 \\
Baik & 10 & 20 \\
Sedang & 26 & 52 \\
Buruk & 14 & 28 \\
\hline Total & 50 & 100
\end{tabular}

Tabel 4. Hasil pemeriksaan indeks plak gigi sesudah penyuluhan

\begin{tabular}{ccc}
\hline Kategori & $\mathrm{n}$ & $\%$ \\
\hline Sangat Baik & 13 & 26 \\
Baik & 32 & 64 \\
Sedang & 5 & 10 \\
Buruk & 0 & 0 \\
\hline Total & 50 & 100 \\
\hline
\end{tabular}

Tabel 5. Hasil Analisis uji Wilcoxon

\begin{tabular}{llccc}
\hline & & $\mathrm{n}$ & $\begin{array}{c}\text { Mean } \\
\text { Rank }\end{array}$ & $\begin{array}{c}\text { Sum of } \\
\text { Ranks }\end{array}$ \\
\hline & $\begin{array}{l}\text { Negative } \\
\text { Ranks }\end{array}$ & $47^{\mathrm{a}}$ & 27.00 & 1269.00 \\
Plak_post_num, & $\begin{array}{l}\text { Positive } \\
\text { Plak_pre_num }\end{array}$ & $3^{\mathrm{b}}$ & 2.00 & 6.00 \\
& $\begin{array}{l}\text { Ranks } \\
\text { Ties }\end{array}$ & $0^{\mathrm{c}}$ & & \\
& Total & 50 & & \\
\hline
\end{tabular}

Tabel 6. Perbandingan rerata indeks plak gigi sebelum penyuluhan dan indeks plak gigi sesudah penyuluhan

\begin{tabular}{lccc}
\hline & $\mathrm{n}$ & $\begin{array}{c}\text { Rerata } \pm \\
\text { s.b }\end{array}$ & $\mathrm{P}$ \\
\hline $\begin{array}{l}\text { Indeks plak } \\
\text { sebelum }\end{array}$ & 50 & $1,53 \pm 0,62$ & \\
$\begin{array}{l}\text { Indeks plak } \\
\text { sesudah }\end{array}$ & 50 & $0,43 \pm 0,36$ & $<0,001$ \\
\hline
\end{tabular}




\section{BAHASAN}

Pada penelitian ini peneliti ingin mengetahui pengaruh penyuluhan cara menyikat gigi terhadap indeks plak gigi pada siswa kelas V SD Inpres Lapangan. Peneliti memberikan penyuluhan tentang cara menyikat gigi dengan metode bass dan metode roll. Salah satu metode penyuluhan yang tepat digunakan untuk anak sekolah dasar yaitu dengan metode demonstrasi. Metode demonstrasi yaitu dengan memperlihatkan cara melakukan suatu tindakan atau prosedur, dengan diberikan penerangan secara lisan, gambar, dan ilustrasi. ${ }^{11}$ Sebelum melakukan penelitian ini peneliti tidak memberikan hadiah kepada responden agar menghindari bias pada saat melakukan penelitian.

Penelitian ini merupakan penelitian quasy eksperimental tanpa adanya kelompok kontrol, sehingga pengambilan data dilakukan dua kali yaitu sebelum dilakukan penyuluhan cara menyikat gigi dan sesudah dilakukan penyuluhan cara menyikat gigi. Pada penelitian ini didapatkan subjek penelitian sebanyak 50 siswa, yang terdiri dari 26 siswa laki-laki (52\%) dan 24 siswa perempuan (48\%). Distribusi karakterisik berdasarkan usia, yaitu siswa yang berusia 10 tahun sebanyak 27 siswa (54\%), dan yang berusia 11 tahun sebanyak 23 siswa $(46 \%)$. Hasil pemeriksaan indeks plak gigi sebelum penyuluhan yaitu kategori sedang sebanyak 26 siswa (52\%), sedangkan sesudah penyuluhan yaitu kategori baik sebanyak 32 siswa (64\%). Data ini dapat dilihat pada tabel 1 hingga tabel 4 .

Berdasarkan hasil penelitian didapatkan nilai rerata indeks plak sebelum penyuluhan cara menyikat gigi sebesar 1,53 dengan kategori sedang dan setelah diberikan penyuluhan tentang cara menyikat gigi nilai rerata berkurang menjadi 0,43 dengan kategori baik. Data ini dapat dilihat pada tabel 6. Berdasarkan dari hasil uji statistik Wilcoxon signed rank test menyatakan terdapat pengaruh yang bermakna dari penyuluhan cara menyikat gigi. Setelah dilakukan penyuluhan cara menyikat gigi sebanyak 47 siswa indeks plaknya menjadi lebih rendah namun ada 3 siswa yang indeks plaknya tetap. Data ini dapat dilihat pada tabel 5.

Ketidakberhasilan dalam menurunkan indeks plak gigi pada ketiga siswa tersebut dipengaruhi oleh beberapa faktor antara lain, siswa tidak memperhatikan dengan benar pada saat peneliti melakukan penyuluhan. Walaupun ada 3 siswa yang tidak berhasil, tapi dengan menurunnya indeks plak pada 47 siswa maka didapatkan nilai $\mathrm{p}<0,001$ dengan problabilitas lebih kecil dari 0,05 $(\mathrm{p}<0,05)$.Berdasarkan hasil ini maka $\mathrm{H}_{0}$ ditolak karena ada pengaruh dari penyuluhan cara menyikat gigi terhadap indeks plak gigi pada siswa kelas V SD Inpres Lapangan.

Penurunan indeks plak gigi disebabkan karena peneliti memberikan penyuluhan tentang kesehatan gigi dan mulut terlebih khusus tentang cara menyikat gigi yang benar sebelum dilakukan penilaian terhadap indeks plak terakhir. Dengan penyuluhan ini siswa-siswa akan bertambah pengetahuannya sehingga diharapkan dapat bersikap dan berperilaku sadar dalam menjaga kesehatan gigi dan mulutnya, serta dapat diterapkan sehari-hari. Penurunan terjadi karena pada usia 10-12 tahun minat belajar dari anak tinggi dan didukung oleh ingatan anak yang mencapai intensitas paling besar dan paling kuat, serta kemampuan dalam menangkap dan memahami materi yang diberikan. ${ }^{12}$

Hasil penelitian ini sejalan dengan penelitian yang pernah dilakukan Ilyas di SD Desa Padang Loang Kecamatan Patampanua yaitu plak awal sebelum penyuluhan yaitu nilai plak awal sebesar 3,55 menjadi 1,28 setelah dilakukannya penyuluhan. ${ }^{5}$ Selain itu penelitian yang sama juga pernah dilakuan Vera di Medan, dimana terjadi penurunan indeks plak sebelum dan sesudah, yaitu nilai indeks plak sebelum ialah 2,82 dan nilai indeks plak sesudah ialah 1,06. ${ }^{4}$ Berdasarkan dari hasil penelitian yang telah dilakukan oleh Riyanti pada siswa-siswi Sekolah Dasar Islam Terpadu (SDIT) Imam Bukhari yang sama dengan peneliti bahwa terdapat adanya perbedaan antara indeks plak sebelum dan sesudah dilakukannya pendidikan penyikatan gigi, maka pada nilai ratarata indeks plak pada kunjungan pertama yaitu 0,23 sedangkan pada kunjungan terakhir memiliki indeks plak yaitu $0,46 .^{12}$

Proses dari belajar yang diberikan melalui program penyuluhan dan pelatihan dapat dimengerti dan dipraktekkan dalam keseharian siswa, sehingga dengan penyuluhan peragaan memiliki dampak yang efektif dalam menunjang 
peningkatan kebersihan gigi dan mulut pada anak sekolah dasar. ${ }^{2}$ Peragaan lebih efektif dalam menurunkan indeks plak dibandingkan dengan menggunakan metode lain. Metode peragaan membantu anak mengingat bagian-bagian gigi yang biasa disikat sewaktu dirumah sehingga anak lebih mengerti ketika ditunjukkan bagian-bagian gigi yang harus disikat di alat peraga. ${ }^{4}$ Penurunan dapat terjadi karena siswa telah sering mempraktekkan penyikatan gigi secara baik dan benar dirumah. Didukung dengan kepedulian siswa terhadap pemeliharaan kesehatan gigi dan mulut juga sudah cukup baik, sehingga tingkat kebersihan gigi dan mulut tetap terjaga. ${ }^{12}$

\section{SIMPULAN}

Penyuluhan cara menyikat gigi dan pelatihan cara menyikat gigi yang diberikan kepada siswa SD Inpres Lapangan memiliki pengaruh dalam menurunkan indeks plak gigi. Indeks plak gigi sebelum dilakukan penyuluhan ialah kategori sedang. Indeks plak gigi sesudah dilakukan penyuluhan yaitu kategori baik.

\section{SARAN}

1. Perlu adanya upaya berkelanjutan dari tenaga kesehatan kedokteran gigi untuk terus memberikan informasi tentang cara menyikat gigi kepada siswa sekolah dasar.

2. Perlu menambah dan memperbanyak informasi dibidang kedokteran gigi tentang penyuluhan cara menyikat gigi terhadap indeks plak

3. Perlu adanya upaya berkelanjutan antara pihak sekolah dan tenaga kesehatan gigi agar siswa-siswa sekolah dasar bisa menjaga kesehatan gigi dan mulut dengan baik dan benar.

\section{DAFTAR PUSTAKA}

1. Departemen kesehatan Republik Indonesia. Laporan hasil riset kesehatan dasar (Riskesdas) nasional 2013. Jakarta: Badan penelitian dan Pengembangan Kesehatan; 2013.h.111-7.

2. Hastuti S, Andriyani A. Perbedaan pengaruh pendidikan kesehatan gigi dalam meningkatkan pengetahuan tentang kesehatan gigi pada anak di SD Negeri 2 Sambi
Kecamatan Sambi Kabupaten Boyolali. Gaster. 2010;7(2):624-32.

3. Bahar A, Andreas P, Herwanda. Efek sakit gigi terhadap konsentrasi belajar pada muridmurid sekolah dasar pengunjung klinik gigi rumah sakit Zainul Abidin Banda Aceh. Dentika Journal. 2010;15(2):120-4.

4. Vera H. Efektifitas metode pengajaran cara menyikat gigi terhadap penurunan indeks plak anak usia 3-5 tahun. Dentika Dental Journal.2010;15(1):42-5.

5. Ilyas M, Putri IN. Efek penyuluhan metode demonstrasi menyikat gigi terhadap penurunan indeks plak gigi pada murid sekolah dasar. Dentofasial Jurnal Kedokteran Gigi. 2012;11(2): 91-5.

6. Hamsar A. Perbandingan sikat gigi yang berbulu halus (soft) dengan sikat gigi yang berbulu sedang (medium) terhadap manfaatnya menghilangkan plak pada anak usia 9-12 tahun di SD Negeri 060830 Kecamatan Medan Petisah tahun 2005. Jurnal Ilmiah PANMED. 2006;1(1):20-3.

7. Anitasari S, Rahayu NE. Hubungan frekuensi menyikat gigi dengan tingkat kebersihan gigi dan mulut siswa sekolah dasar negeri di kecamatan Palaran kotamadya Samarinda provinsi Kalimantan Timur. Dental Journal. 2005;38(2):88-90.

8. Arief EM, Adnan NDB, Awang RAR. The effect of chlorhexidine and triclosan on undisturbed plaque formation for 72 hours duration. Dentofasial Jurnal Kedokteran Gigi. 2010;9(1):1-6.

9. Palupi DN, Rachmawati D, Dewi APK. Perbedaan efektivitas sikat gigi elektrik dengan sikat gigi manual terhadap penurunan indeks plak pada anak tunagrahita di SDLB Putra Jaya Malang. [cited 2014 May 10]. Available from: http://old.fk.ub.ac.id/artikel/id/filedownload/g igi/MAJALAH_Adelia\%20Putri\%20Kharism a\%20D_105070400111043.pdf.

10. Darby ML, Walsh MM. In: Dolan JJ, editor. Dental Hygiene Theory and Practice $\left(3^{\text {rd }} \mathrm{Ed}\right)$. Canada: Saunders Elsevier, 2010.p.281-395.

11. Putri IN. Efek penyuluhan kesehatan gigi dan mulut dengan demonstrasi cara menyikat gigi terhadap penurunan indeks plak pada 
murid kelas VI Sekolah Dasar di Desa Padang Loang Kecamatan Patampanua Kabupaten Pinrang. [cited 2014 May 7]. Available from:

http://repository.unhas.ac.id/bitstream/handle/ 123456789/2448/SKRIPSI\%20INDAH\%20N ISITA\%20PUTRI.docx? sequence $=4$.
12. Riyanti E, Chemiawan E, Rizalda RU. Hubungan Pendidikan Penyikatan Gigi Dengan Tingkat Kebersihan Gigi dan Mulut Siswa-siswi Sekolah Dasar Islam Terpadu (SDIT) Imam Bukhari. Jurnal Kedokteran Gigi. 2005;17:103-8. 